\title{
Adult height and mortality in London: early life, socioeconomic confounding, or shrinkage?
}

\author{
David A Leon, George Davey Smith, Martin Shipley, David Strachan
}

\begin{abstract}
Study objective - To examine in detail the cause specific associations between height and mortality.

Design - A prospective cohort study with an 18 year mortality follow up.

Setting and participants - The Whitehall study of 18403 men in the civil service in London examined between 1967 and 1969 aged 40-64 and followed up for mortality until the end of January 1987.

Main results - There was considerable variation in the strength of height-mortality association by cause. Respiratory disease showed the strongest inverse association, cardiovascular disease a moderate effect, and all neoplasms virtually no effect. Adjustment for age and civil service grade reduced the strength of these associations slightly, but had no impact on the heterogenous pattern by cause $\left(\chi^{2}\right.$ $3 d f \quad p<0.001)$. The height-mortality association declined with the length of follow up. By $15+$ years, the only appreciable height affect was for respiratory disease mortality.

Conclusions - The attenuation of the height-mortality association with length of follow up might be explained by differential height reduction before entry that was greatest for people who were already ill, and hence at greatest risk of dying. The cause specific variation in the heightmortality association lends little support to the contention that impaired growth in childhood is a marker of general susceptibility to disease in adulthood.
\end{abstract}

( $f$ Epidemiol Community Health 1995;49:5-9)

Adult height has been found to be predictive of mortality in cohort studies in Britain, ${ }^{1}$ Norway, ${ }^{2}$ Finland, ${ }^{3}$ and Sweden. ${ }^{45}$ Most studies have reported results for only a few causes of death, the strongest effects being for mortality from respiratory and coronary heart disease, and death rates have been shown to decline as height increases. These effects have been found to persist after adjusting for socioeconomic circumstances in adult life, ${ }^{16}$ childhood, ${ }^{3}$ and both simultaneously. ${ }^{4}$ Similarly, the association between height and cardiovascular disease incidence or mortality has been found to survive statistical adjustment for risk factors such as smoking, blood pressure, cholesterol concentration, body mass index, and lung function. ${ }^{6-9}$ Since attained adult height is thought to be partly determined by circumstances in utero, infancy, and childhood through to adolescence, ${ }^{1011}$ the association of height with mortality has been viewed as supporting the hypothesis that early life and childhood factors directly influence mortality in adulthood. ${ }^{1212}$

One of the first reports of the association of height with mortality came from the 10 year follow up of the Whitehall study of male, British civil servants. ${ }^{16}$ We were prompted to re-examine the height relationship in the Whitehall study based on an extended follow up period of 18 years because of the increasing interest in the contribution of early life experiences to adult health. ${ }^{13}$

\section{Methods}

In the Whitehall study, 18403 men aged 40-64 were examined between 1967 and 1969. Measurements included height, weight, and blood pressure. A questionnaire was completed regarding age, civil service employment grade, smoking habits, and health status. Height was measured with the subject wearing shoes and standing back to the measuring rod with the visual axis horizontal; readings were recorded to the nearest $\frac{1}{2}$ inch below. Full details of procedures used in the screening examination have been reported previously. ${ }^{14}$

Employment grade was categorised as administrative, professional or executive, clerical, and "other grades" (men in messenger and other unskilled manual jobs). Employment grade was not comparable to the rest of the sample for 873 subjects from the Diplomatic Service and British Council. These subjects have been classified as a separate group in the analyses that involve grade. Smoking has been categorised according to cigarette use as "current smoker", "ex-smoker", and "never smoker". Disease on entry to the cohort was defined as any one or more of the following: relative shortness of breath on level ground, pain in either leg on walking, past history of diabetes, heart or blood pressure trouble, unexplained weight loss over the preceding year, grade 1 or 2 angina according to the Rose angina questionnaire, severe chest pain for over half an hour and an abnormal ECG according to the following Minnesota code items: Q/QS waves $(1 \cdot 1-1 \cdot 3)$; ST depressions $(4 \cdot 1-4 \cdot 4)$; T wave inversion or flattening $(5 \cdot 1-5 \cdot 3)$; or leftbundle branch block $(7 \cdot 1)$.

Records from over $99 \%$ of subjects were traced and flagged at the National Health Service Central Registry, and this almost complete mortality follow up to 31 January 1987 provides the basis for the analysis. Cause of death from death certificates were coded according to the 
Table 1 Number of deaths and mortality rate ratios (95\% CI) for broad cause groups associated with a 6 in difference in height (short $v$ tall)

\begin{tabular}{|c|c|c|c|}
\hline \multirow[t]{2}{*}{ Cause of death (ICD8 code) } & \multirow{2}{*}{$\begin{array}{l}\text { No of } \\
\text { deaths }\end{array}$} & \multicolumn{2}{|l|}{ Adjustments } \\
\hline & & Age & Age and grade \\
\hline $\begin{array}{l}\text { All causes (0001-9999) } \\
\text { Malignant neoplasms }(140-209) \\
\text { Circulatory disease }(390-458) \\
\text { Respiratory disease }(460-519) \\
\text { All other causes }\end{array}$ & $\begin{array}{l}4189^{*} \\
1290 \\
2198 \\
348 \\
340\end{array}$ & $\begin{array}{l}1.21(1.13,1.29) \\
0.98(0.87,1.11) \\
1.25(1.14,1.37) \\
1.90(1.52,2.38) \\
1.27(1.00,1.61)\end{array}$ & $\begin{array}{l}1.12(1.04,1.20) \\
0.91(0.80,1.03) \\
1.18(1.07,1.30) \\
1.60(1.28,2.02) \\
1.16(0.91,1.48)\end{array}$ \\
\hline$\chi^{2}$ heterogeneity ( $\left.3 \mathrm{df}\right)$ & & $\begin{array}{l}27 \cdot 35 \\
(p<0 \cdot 001)\end{array}$ & $\begin{array}{l}21.65 \\
(p<0.001)\end{array}$ \\
\hline
\end{tabular}

* All cause mortality includes 13 deaths whose specific cause of death was not known.

eighth revision of the International Classification of Diseases (ICD).

Mortality rates have been calculated using person years at risk. Age and grade adjusted mortality rate ratios and their confidence intervals have been estimated using Cox's proportional hazards regression model. The effect of height on mortality is expressed as the mortality rate ratio associated with a six inch difference in height derived from regression models in which height (as a continuous variable) was included as a linear term. Tests of linear trend in mortality ratios across the period of follow up have been calculated by testing the proportional hazards assumption. All analyses were performed using the statistical package $S A S$.

\section{Results}

HEIGHT EFFECTS BY CAUSE

The age adjusted associations between height at entry to study and mortality by cause group are shown in table 1. Respiratory disease shows the strongest inverse association, mortality declining with height. Smaller effects in the same direction are seen for circulatory disease and "all other causes". No effect is seen for the aggregate of all malignant neoplasms. Additional adjustment for civil service grade reduces all of the rate ratios, although there remains an appreciable effect for respiratory disease. It is highly unlikely that the variation in the effects across cause groups is due to chance.
In table 2, the height effects are presented for specific causes of death. Within circulatory disease there are striking differences in the effects which are unlikely to be due to chance. Mortality from coronary heart disease and cerebrovascular disease show moderate decreases with increasing height. The opposite is found for mortality from aortic aneurysm: tall people are at increased risk relative to those who were short. Adjustment for civil service grade results in small reductions in the circulatory disease rate ratios.

Mortality from bronchitis and emphysema, and the aggregate of other respiratory diseases, show similar strong inverse associations with height. Adjustment for grade reduces the rate ratios substantially, although they remain large compared to other causes.

The association of height with mortality from specific malignant neoplasms reveals no consistent direction of effect. The strongest effect is seen for oesophageal cancer, with adjusted rate ratios of over 2 associated with a 6 in reduction in height. Of the 12 cancer sites shown in table 2 , the age adjusted rate ratios are above 1.00 for 5 sites. Adjustment for grade in addition to age, reduces most of the rate ratios, but the mixed patterns of effect are still apparent, although a formal test of heterogeneity suggests that these site specific differences could have arisen by chance alone.

HEIGHT EFFECTS BY PERIOD OF FOLLOW UP A pronounced attenuation of the height effects with period of follow up is shown in table 3 for all causes, coronary heart disease, and respiratory disease. For all three cause groups, the linear trend statistic is statistically significant. The reduction in the rate ratios with follow-up is most apparent for respiratory disease, although at $15+$ years there remains an inverse association between height and mortality. For coronary heart disease, the rate ratios also decline, to such an extent that by the last follow up period there is virtually no height effect apparent.

Table 2 Mortality rate ratios (95\% CI) for specific causes associated with a 6 in difference in height (short $v$ tall)

\begin{tabular}{|c|c|c|c|}
\hline \multirow[t]{2}{*}{ Cause of death (ICD8 code) } & & \multicolumn{2}{|l|}{ Adjustments } \\
\hline & & Age & Age and grade \\
\hline $\begin{array}{l}\text { Coronary heart disease }(410-414) \\
\text { Cerebrovascular disease }(430-438) \\
\text { Aortic aneurysm (441) } \\
\text { Other circulatory disease (remainder } 390-458) \\
\chi^{2} \text { heterogeneity (3df) }\end{array}$ & & $\begin{array}{l}1.33(1.20,1.49) \\
1.37(1.05,1.78) \\
0.63(0.41,0.99) \\
0.94(0.70,1.26) \\
14.56 \\
(\mathrm{p}<0.01)\end{array}$ & $\begin{array}{l}1.27(1.14,1.42) \\
1.29(0.99,1.69) \\
0.58(0.37,0.90) \\
0.86(0.64,1.15) \\
16.71 \\
(\mathrm{p}<0.001)\end{array}$ \\
\hline $\begin{array}{l}\text { Bronchitis and emphysema }(490-492) \\
\text { Other respiratory (460-489, 493-519) } \\
\chi^{2} \text { heterogeneity (1df) }\end{array}$ & & $\begin{array}{l}2 \cdot 08(1 \cdot 36,3 \cdot 20) \\
1 \cdot 84(1 \cdot 41,2 \cdot 39) \\
0 \cdot 24 \\
(p>0 \cdot 5)\end{array}$ & $\begin{array}{l}1.58(1 \cdot 01,2 \cdot 45) \\
1 \cdot 61(1 \cdot 23,2 \cdot 11) \\
0 \cdot 01 \\
(p>0 \cdot 5)\end{array}$ \\
\hline $\begin{array}{l}\text { Lung cancer } \\
\text { Oesophagus cancer } \\
\text { Stomach cancer } \\
\text { Pancreas cancer } \\
\text { Colon cancer } \\
\text { Rectum cancer } \\
\text { Prostate cancer } \\
\text { Bladder cancer } \\
\text { Brain cancer } \\
\text { Leukaemia } \\
\text { Lymphoma } \\
\text { Other cancers } \\
\chi^{2} \text { heterogeneity (11df) }\end{array}$ & $\begin{array}{l}(162) \\
(150) \\
(151) \\
(157) \\
(153) \\
(154) \\
(185) \\
(188) \\
(191) \\
(204-207) \\
(200-203) \\
\text { (remainder } 140-209)\end{array}$ & $\begin{array}{l}1.06(0.86,1.30) \\
2.34(1.18,4.64) \\
1.23(0.80,1.90) \\
1.11(0.65,1.89) \\
1.04(0.70,1.55) \\
0.99(0.51,1.93) \\
0.63(0.41,0.99) \\
0.98(0.52,1.85) \\
0.57(0.28,1.15) \\
0.88(0.45,1.72) \\
0.56(0.31,1.01) \\
0.94(0.68,1.31) \\
17.64 \\
(p=0.09)\end{array}$ & $\begin{array}{l}0.89(0.73,1.10) \\
2.14(1.07,4.29) \\
1.07(0.69,1.65) \\
1.08(0.63,1.85) \\
1.07(0.71,1.60) \\
0.97(0.48,1.94) \\
0.70(0.45,1.11) \\
1.00(0.53,1.89) \\
0.56(0.28,1.15) \\
0.91(0.46,1.81) \\
0.53(0.29,0.96) \\
0.86(0.06,1.21) \\
13.72 \\
(p=0.25)\end{array}$ \\
\hline
\end{tabular}


Table 3 Cause specific mortality rate ratios (95\% CI) associated with a 6 in difference in height (short $v$ tall) by period of follow up

\begin{tabular}{|c|c|c|c|}
\hline \multirow[t]{2}{*}{ Cause of death } & \multirow{2}{*}{$\begin{array}{l}\text { Period of follow up } \\
\text { (y) }\end{array}$} & \multicolumn{2}{|l|}{ Adjustments } \\
\hline & & Age & Age and grade \\
\hline \multicolumn{4}{|l|}{ All causes } \\
\hline & $\begin{array}{c}0-9 \\
10-14 \\
15+\end{array}$ & $\begin{array}{l}1.36(1.23,1.51) \\
1.15(1.03,1.30) \\
1.04(0.91,1.19)\end{array}$ & $\begin{array}{l}1.23(1.11,1.37) \\
1.09(0.97,1.23) \\
0.98(0.86,1.13)\end{array}$ \\
\hline Test of linear trend & & $\mathrm{p}<0.01$ & $\mathrm{p}<0.01$ \\
\hline \multicolumn{4}{|l|}{ Malignant neoplasms } \\
\hline & $\begin{array}{c}0-9 \\
10-14\end{array}$ & $\begin{array}{l}1.01(0.83,1.22) \\
1.00(0.81,1.23)\end{array}$ & $\begin{array}{l}0.90(0.74,1.09) \\
0.94(0.76,1.17)\end{array}$ \\
\hline Test of linear trend & $15+$ & $\begin{array}{l}0.92(0.71,1.18) \\
p>0.5\end{array}$ & $\begin{array}{l}0.88(0.68,1.13) \\
\mathrm{p}>0.5\end{array}$ \\
\hline \multicolumn{4}{|l|}{ Connary heart disease } \\
\hline & $\begin{array}{l}0-9 \\
10-14 \\
15+\end{array}$ & $\begin{array}{l}1.56(1.33,1.83) \\
1.24(1.02,1.50) \\
1.07(0.85,1.34)\end{array}$ & $\begin{array}{l}1.44(1.23,1.67) \\
1.20(0.99,1.47) \\
1.06(0.83,1.34)\end{array}$ \\
\hline Test of linear trend & & $\mathrm{p}<0.01$ & $\mathrm{p}<0.01$ \\
\hline \multicolumn{4}{|l|}{ Respiratory disease } \\
\hline & $\begin{array}{l}0-9 \\
10-14 \\
15+\end{array}$ & $\begin{array}{l}3.26(2 \cdot 20,4 \cdot 82) \\
1.58(1.10,2 \cdot 28) \\
1.42(0.95,2 \cdot 13)\end{array}$ & $\begin{array}{l}2.64(1.76,3.97) \\
1.33(0.92,1.92) \\
1.25(0.83,1.89)\end{array}$ \\
\hline Test of linear trend & & $\mathrm{p}=0.04$ & $\mathrm{p}=0.04$ \\
\hline \multicolumn{4}{|l|}{ All other causes } \\
\hline & $\begin{array}{c}0-9 \\
10-14\end{array}$ & $\begin{array}{l}1.23(0.98,1.55) \\
1.10(0.86,1.41)\end{array}$ & $\begin{array}{l}1.13(0.90,1.42) \\
1.04(0.81,1.34)\end{array}$ \\
\hline Test of linear trend & $15+$ & $\begin{array}{l}1.01(0.77,1.33) \\
p=0.4\end{array}$ & $\begin{array}{l}0.91(0.70,1 \cdot 20) \\
p=0.4\end{array}$ \\
\hline
\end{tabular}

Table 4 Mortality rate ratios (95\% CI) for broad cause groups associated with a 6 in difference in height (short $v$ tall), excluding subjects with evidence of pre-existing disease on entry to study

\begin{tabular}{lll}
\hline Cause of death (ICD8 code) & Adjustments \\
\cline { 2 - 3 } & Age & Age and grade \\
\hline All causes (0001-9999) & $1 \cdot 11(1 \cdot 02,1 \cdot 29)$ & $1 \cdot 04(0.95,1 \cdot 13)$ \\
Malignant neoplasms (140-209) & $1 \cdot 00(0 \cdot 87,1 \cdot 16)$ & $0.92(0 \cdot 80,1 \cdot 07)$ \\
Circulatory disease (390-458) & $1 \cdot 13(0 \cdot 99,1 \cdot 28)$ & $1 \cdot 06(0.93,1.20)$ \\
Respiratory disease (460-519) & $1 \cdot 70(1 \cdot 24,2 \cdot 33)$ & $1 \cdot 52(1 \cdot 11,2 \cdot 08)$ \\
All other causes & $1 \cdot 11(0 \cdot 83,1 \cdot 49)$ & $1 \cdot 06(0 \cdot 79,1.43)$ \\
\hline
\end{tabular}

\section{EXCLUSION OF THOSE WITH PRE-EXISTING} DISEASE

At entry to study, men with evidence of preexisting disease were 0.28 in $(95 \%$ CI $0 \cdot 19$ 0.37 ) shorter than those without after adjustment for age and grade. Table 4 shows the age and age and grade adjusted rate ratios by cause group having excluded subjects with disease on entry. With the exception of malignant neoplasms, the rate ratios in table 4 are smaller than in table 1 , only the association with respiratory disease remaining of appreciable size after adjustment for age and grade.

Adjustment for current smoking habit, in addition to age and grade, had very little effect upon the height-mortality effects reported above.

\section{Discussion}

Our analyses provide a much more detailed picture of the associations between height and mortality in the Whitehall study than published previously. ${ }^{16}$ The cause specific patterns found are similar to those reported by Waaler, ${ }^{2}$ who found the strongest associations to be with mortality from obstructive lung disease, slightly weaker associations with mortality from cardiovascular disease as a whole, and no association for the aggregate of all cancers. However, the only other study to report data on the height- mortality association for a broader range of causes $^{5}$ (based on a cohort of Swedish conscripts) did not find the same relationships: tall people were at increased risk of death from neoplasms and the aggregate of cardiovascular and respiratory diseases. In this Swedish study, height was measured at age 18 , while in the Whitehall and Norwegian ${ }^{2}$ studies height was measured among people most of whom were considerably older. A study based on heights measured among a random sample of the entire Swedish population, however, found the usual inverse association between height and mortality from cardiovascular disease. ${ }^{4}$ A study of the association of self reported height with the prevalence of self reported chronic disease in the Italian national health survey ${ }^{15}$ found the largest effects (adjusted for education, smoking, and region of residence) to be for respiratory diseases, smaller effects for cardiovascular disease and no effect for cancer.

One of the most striking variations between causes in the height effect in the Whitehall data is within circulatory disease. Height is inversely related to mortality from coronary heart and cerebrovasculalr disease, but positively related to mortality from aortic aneurysm. The correlation of aortic aneurysm mortality with height was not confined to the tallest men, nor to dissecting aneurysms, so it is unlikely that it can be entirely explained by the recognised vascular complications of Marfan's syndrome. ${ }^{16}$

There have been a variety of studies of height and cancer risk among men, although there is little consistency in their findings. ${ }^{17}$ The positive associations between height and cancer risk found in several studies have been taken to indicate that high calorie intake in early life increases risk of cancer in adulthood, ${ }^{18}{ }^{19}$ a suggestion that receives some support from animal experiments. ${ }^{18}$ It is interesting to note that the apparent increase in mortality from lymphomas with increasing height reported here is consistent with the finding that a series of Hodgkin's lymphoma patients were taller than their matched controls. ${ }^{20}$

The hypotheses advanced to explain why adult height may have an effect upon mortality tend to emphasise height as a proxy for circumstances in infancy and childhood. That height is associated with mortality, however, could be due to confounding, particularly by socioeconomic factors. Adult height is related to socioeconomic position, ${ }^{2122}$ and socioeconomic position is related to a range of risk factors. In the Whitehall study, civil service grade has been shown to be a powerful predictor of subsequent mortality. ${ }^{1}$ As a measure of socioeconomic position, it is highly correlated with circumstances in adult life, and risk factors for mortality including plasma cholesterol concentration, respiratory function, and blood pressure. The grade adjusted height effects in the Whitehall study, which remain appreciable for respiratory disease, and to a lesser extent coronary heart disease, could therefore be regarded as evidence for aetiological factors operating in childhood, infancy, or even in utero. However, residual confounding may also be present. Grade may not reflect the full subtlety 
of socioeconomic circumstances in adult life ${ }^{6}$ and thus the adjusted effects may overestimate the true effect of height as a proxy for childhood circumstances. Acting in the reverse direction, it is possible that the adjusted effects underestimate the influence of childhood circumstances, as within grade, differences in height may have a larger genetic component than variations in height in the study population as a whole. That socioeconomic confounding is not the only explanation is suggested by the fact that very similar associations were observed between height and cardiovascular disease in the socioeconomically homogenous US study population of male physicians. ${ }^{8}$

It was shown earlier that age and grade adjusted height effects vary by broad cause of death group. ${ }^{6}$ This variation in effect is even more marked in the detailed cause specific analyses we present here. We thus conclude that these Whitehall data provide little support for the contention ${ }^{123}$ that circumstances in infancy and childhood influence susceptibility in adulthood to disease in general.

It has been suggested ${ }^{24}$ that the positive association seen between upward social mobility and height may explain part of the heightmortality association: taller people being more likely to reap the health benefits of better socioeconomic circumstances in adulthood, regardless of their socioeconomic position in childhood. Waaler, ${ }^{2}$ who was the first to systematically report the association between height and mortality, discussed the significance of height as a proxy for childhood circumstances, as well as the possibility that genetic regulation of height and susceptibility to disease may be linked in some way. Intriguingly, however, he also considered that reverse causality might be important, in that "diseases . . . might lead to shorter body height . . . and of course also to excess mortality" (p 34). Measured height could decline as a consequence of the onset of morbidity which ultimately leads to death. This "shrinkage" might be due to postural changes, some of which may be organic, such as kyphosis among men with obstructive lung disease.

Our findings that the main height-mortality associations are attenuated with length of follow up are consistent with this "shrinkage" explanation. There is a parallel with the healthy worker effect. ${ }^{25}$ Mortality rates among cohorts of people in employment at the start of follow up are usually lower than those in the general population. This health advantage is strongest at the start of follow up, but wears off with duration of follow up, as the prevalence of disease increases and a proportion of those who become sick fall out of employment. The decline in the height effect with length of follow up observed in our analyses could be a similar "wearing-off" of a selection effect. The parallel with the healthy worker effect extends to the way in which shrinkage affects different causes of death. While the healthy worker effect has little impact on mortality from malignant neoplasms, the mortality advantage from cardiovascular disease is generally eliminated within five to 10 years, while that for respiratory dis- ease remains more substantial and persists over a much longer period. ${ }^{26}$ However, it should be emphasised that the healthy worker effect operates in an opposite way to the hypothesised shrinkage effect, as it involves the selection of the "healthy" employed, rather than the selection of the "sick" whose measured height has declined through illness.

If health-related shrinkage explains some of the association, then one would predict that height would show a much reduced effect on mortality in a follow up study if persons with pre-existing disease were excluded at the outset. This is consistent with our finding that the height effects were almost eliminated for all causes other than respiratory disease as a result of the exclusion of those who had evidence of pre-existing disease on entry to study. A similar picture is evident from an analysis of data from the US railroad cohort study ${ }^{27}$ This study recruited three thousand white railway workers aged 40-59 years and followed them up over a 20 year period. The presence of cardiovascular disease at baseline examination was determined by clinical and ECG findings of myocardial infarction, angina, major non-specific ECG abnormalities, peripheral vascular disease and hypertension. When 465 men with evidence of cardiovascular disease at baseline were excluded, there was no association between height and major cardiovascular disease ascertained during follow up. However, exclusion of those with a history of angina in the US physicians study had little impact on the strength of the height-disease association. ${ }^{8}$

Those men with evidence of pre-existing disease at entry to the Whitehall study were $\frac{1}{4}$ in shorter at the start of follow up than those without. How biologically plausible is it that such a height difference could have arisen through shrinkage rather than differences in maximum attained height? A partial answer to this question may be provided by looking at the size of height reductions associated with aging. Longitudinal studies suggest that measured height peaks at the end of the third decade of life, declining with increasing velocity from the end of the fourth decade. ${ }^{2829}$ Forsdahl and Waaler, ${ }^{29}$ in their study of 10000 men and 10000 thousand women in Norway, report reductions of around $1 \mathrm{~mm} / \mathrm{y}$ in each five year age group in the range $45-69$ years. However, by age $80-84$, height declines by $2 \cdot 2 \mathrm{~mm} / \mathrm{y}$. Similar height reductions are reported in two longitudinal studies of "healthy" men in the United States. ${ }^{2830}$ If these height reductions applied to the Whitehall study population, over a 20 year period there would be a mean shrinkage of about $0.8 \mathrm{in}$. Given this degree of "normal" shrinkage, it is possible that a difference of $\frac{1}{4}$ in, or even more, could arise as a result of differential shrinkage between those who have certain types of morbidity and those who do not.

It should be emphasised that our data do not provide any direct evidence for the role of shrinkage as a contributory factor to the heightmortality relationship. In order to quantify the extent to which shrinkage may explain some of the height-mortality association, what is now 
required are data in which longitudinal measurements of height change can be related to morbidity and subsequent mortality. In the meantime, caution should be displayed in interpreting the aetiological significance of the association between height and mortality.

We would like to thank Johan Giesecke, Di Kuh, Chris Power, and Denny Vågerö.

1 Marmot MG, Shipley MJ, Rose G. Inequalities in death specific explanations of a general pattern? Lancet 1984;i: 1003-6.

2 Waaler HT. Height, weight and mortality. Acta Med Scand 1984;679(suppl).

3 Notkola V, Punsar S, Karvonen MJ, Haapakoski J. Socioeconomic conditions in childhood and mortality and morbidity caused by coronary heart disease in adulthood in rural Finland. Soc Sci Med 1985;21:517-23.

4 Peck ANM, Vảgerö D. Adult body height, self perceived health and mortality in the Swedish population. $f$ Epidemio Community Health 1989;43:380-4.

5 Allbeck P, Bergh C. Height, body mass and mortality; Do social factors explain the association? Public Health 1992; 106:375-82.

6 Davey Smith G, Shipley MJ, Rose G. Magnitude and causes of socioeconomic differentials in mortality: further evidence from the Whitehall study. $\mathcal{F}$ Epidemiol Community Health 1990;44:265-70.

7 Yarnell JWG, Limb ES, Layzell JM, Baker IA. Height: a risk marker for ischaemic heart disease: prospective results from the Caerphilly and Speedwell heart disease studies. Eur Heart $\mathcal{F}$ 1992;13:1602-5.

8 Hebert PR, Rich-Edwards JW, Manson JE, Ridker PM Cook NR, O'Connor GT, Buring JE, Hennekens CH. Height and incidence of cardiovascular disease in male physicians. Circulation 1993;88:1437-43.

9 D'Avanzo B, La Vecchia C, Negri E. Height and the risk of acute myocardial infarction in Italian women. $S o c S_{c i}$ of acute myocardial in

10 Eveleth PB, Tanner JM. Worldwide variation in human growth. Cambridge: Cambridge University Press, 1976.

11 Floud R, Wachter K, Gregory A. Height, health and history: nutritional status in the United Kingdom, 1750-1980. Cambridge: Cambridge University Press, 1990.

12 Barker DJP, Osmond C, Golding J. Height and mortality in the counties of England and Wales. Ann Hum Bio 1990;17:1-6.

13 Barker DJP. Fetal and infant origins of adult disease. London:
British Medical Journal, 1992.

14 Reid DD, Brett GZ, Hamilton PJS, Jarrett RJ, Keen H, Rose G. Cardiorespiratory disease and diabetes among middle-aged male civil servants. A study of screening and intervention. Lancet 1974; i:469-73.

15 La Vecchia C, Decarli A, Negri E, Ferraroni M, Pagano R. Height and prevalence of chronic disease. Rev Epidemiol Santé Publique 1992;40:6-14.

16 Strachan DP. Predictors of death from aortic aneurysm among middle-aged men: the Whitehall study. $\mathrm{Br} \mathcal{F}$ Surg 1991;78:401-4.

17. Albanes D, Jones DY, Schatzkin A, Micozzi MS, Taylor PR. Adult stature and risk of cancer. Cancer Res 1988;48: 1658-62.

18 Albanes D, Winick $M$. Are cell number and cell proliferation risk factor for cancer? $\mathcal{F}$ Natl Cancer Inst 1988;80:772-5.

19 Vatten LJ, Kvikstad A, Nymoen EH. Incidence and mortality of breast cancer related to body height and living conditions during childhood and adolescence. Eur 7 Cancer 1992;28:128-31.

20 Hancock BW, Mosely R, Coup AJ. Height and Hodgkin's disease (letter). Lancet 1976;ii: 1364

21 Kuh DL, Power C, Rodgers B. Secular trends in social class and sex differences in adult height. Int $\mathcal{F}$ Epidemiol 1991; 20:1001-9.

22 Walker M, Shaper AG, Wannamethee G. Height and socia class in middle-aged British men. $f$ Epidemiol Community

23 Mackenbach JP. Socio-economic health differences in the Netherlands: A review of recent empirical findings. Soc Sci Med 1992;34:213-26.

24 Peck ANM. Childhood environment, intergenerational mobility, and adult health - evidence from Swedish data. $\mathscr{f}$ Epidemiol Community Health 1992;46:71-4.

25 Carpenter LM. Some observations on the healthy worker effect. Br F Indust Med 1987;44:289-91.

26 Goldblatt P, Fox J, Leon DA. Mortality of employed men and women. Am f Ind Med 1991;20:285-306.

27 Yao CH, Slattery ML, Jacobs DR, Folsom AR, Nelson ET, Anthropometric predictors of coronary heart disease and total mortality: Findings from the US railroad study. $\mathrm{Am}$ total mortality. Findings from

28 Friedlander JS, Costa PT, Bosse R, Ellis E, Rhoads JG, Stoudt HW. Longitudinal physique changes among healthy white veterans at Boston. Hum Biol 1977;49. $541-58$

29 Forsdahl A, Waaler HT. Høydeforandringer i relasjon ti alder. Tidssk Nor Laegeforen 1976;96:211-15.

30 Shock NW. Longitudinal studies of aging in humans. In Finch CE, Schneider EL, eds. Handbook of the biology of aging. New York: Van Nostrand Reinhold Co, 1985; 